\title{
Whistleblowing from an International Perspective: A Comparative Analysis of Institutional Arrangements
}

\author{
Kim Loyens ${ }^{1, *(\mathbb{D})}$ and Wim Vandekerckhove ${ }^{2}$ \\ 1 School of Governance, Utrecht University, Bijlhouwerstraat 6, 3511 ZC Utrecht, The Netherlands \\ 2 Department of Human Resources and Organisational Behaviour, University of Greenwich, \\ London SE10 9LS, UK; W.Vandekerckhove@greenwich.ac.uk \\ * Correspondence: k.m.loyens@uu.nl
}

Received: 27 April 2018; Accepted: 2 July 2018; Published: 5 July 2018

\begin{abstract}
While there appears to be consensus amongst policy makers that legislation to protect whistleblowers is needed, the emerging policy question addresses what institutional framework is most fit to implement whistleblowing legislation. However, the institutions to whom whistleblowers report-which are in the literature addressed as internal or external recipients of whistleblowing concerns-have been given limited scholarly attention. Research has instead focused on motives, behaviour, and experiences of whistleblowers on the one hand, and whistleblowing legislation on the other. Particularly the role of external agencies, like ombudsmen, anti-corruption agencies, and Inspector General offices, in dealing with whistleblowing concerns has been under-studied. With the aim of starting to fill this research gap, this paper reports the findings of a comparative study of governmental whistleblowing agencies (other than courts) and non-governmental whistleblowing protection organizations (NGOs), as important examples of external recipients of whistleblowing concerns, in 11 countries with whistleblowing legislation. The study aimed to find similarities and differences between these agencies, and to identify challenges and dilemmas that the installation of whistleblowing agencies bring about. Data collection was done by means of 21 interviews with academic experts and high-ranking officials within the selected countries, and in-depth analysis of available (policy) documents and reports. This paper finds that in the studied countries, there is a trend to install governmental whistleblowing agencies that combine various tasks to implement whistleblowing legislation (e.g., advice, psychosocial care, investigation of wrongdoing or retaliation, and prevention of wrongdoing). When such agencies are absent or considered weak, NGOs may step in to fill the need. Whereas most governmental whistleblowing agencies have investigative tasks, in Belgium and in the Netherlands, investigations of wrongdoing and retaliation are done within the same department for the reason that these issues cannot be easily separated. Other agencies have separated these tasks to avoid conflict of interest or because different expertise is claimed to be needed for both. Further research is needed to analyze the effects of each institutional approach, and how to avoid conflict of interest, particularly the risk of partial investigations of wrongdoing. Our study also shows that while not many countries provide government funds for specific psychosocial care for whistleblowers, most governmental whistleblowing agencies do give advice to whistleblowers and invest in the prevention of wrongdoing or training of those who implement whistleblowing legislation. While providing important insights into the role of whistleblowing agencies in 11 countries, this study also develops questions for further research.
\end{abstract}

Keywords: whistleblowing; institutions; reporting wrongdoing; comparative study 


\section{Introduction}

Many scholars have studied the motives and experiences of whistleblowers (e.g., Ayers and Kaplan 2005; De Graaf 2010； Loyens 2012; $\quad$ Miceli et al. 1991; $\quad$ Near and Miceli 1996; Roberts 2014; Rothschild and Miethe 1999). Whistleblowing policies and legislation in different countries have also been studied extensively either by scholars using a comparative law perspective (see e.g., Dworkin and Brown 2013; Fasterling and Lewis 2014; Lewis and Trygstad 2009; Morvan 2009; Vaughn 2012), or by international organisations (BluePrint for Free Speech 2015; OECD 2011; Osterhaus and Fagan 2009; PACE Parliamentary Assembly of the Council of Europe; UNODC 2015). However, the agencies that receive reports made by whistleblowers-in the whistleblowing literature referred to as internal or external recipients 'who can effect action' (Miceli and Near 1992, p. 16) — have been given much less attention in academia (Brown et al. 2014; Moberly 2014). Several scholars (Miceli and Near 1992; Miceli et al. 2008) have argued that it is important to study the role of internal and external recipients of whistleblowing concerns. Their responsiveness and how that is perceived by would-be whistleblowers can affect the decision to report or not. This study focuses on external recipients, particularly on (1) government agencies (other than courts) that receive reports about alleged wrongdoing in other organisations and/or alleged retaliation against those who blew the whistle-which may include Ombudsmen, anti-corruption agencies, Inspector General offices, and the Securities and Exchange Commission (Moberly 2014; Roberts and Brown 2010); and (2) civil society organisations or non-governmental organisations (NGOs) that receive whistleblower disclosures and-often in a more activist way-try to enhance whistleblower protection. We do not focus on the media in their role as an external recipient of concerns (Bosua et al. 2014; Vandekerckhove 2010).

Research suggests that whistleblowing reports are an important source of information to uncover wrongdoing within organizations (Brown, Mazurski and Olsen 2008, cited in Lewis et al. 2014). External recipients of concerns are considered crucial for effectively ending the wrongdoing, because internal recipients (like a supervisor) may be more inclined to cover up or ignore the problem (Dworkin and Baucus 1998; Mesmer-Magnus and Viswesvaran 2005; Moberly 2014). At the same time, organisations often prefer whistleblowers to use internal reporting channels (see also Meerts, THIS ISSUE), as to avoid possible damage to reputation and disruption of employer-employee relations if concerns are discussed outside the organisation (Moberly 2014). The few studies that have analyzed the role of external recipients have focused on the effectiveness of whistleblowers to stop the wrongdoing (Miceli and Near 2002) and recipients' satisfaction with whistleblowing processes linked to procedural and distributive justice of whistleblowing channels (Near et al. 1993). However, not much empirical evidence is available about the actual role and tasks of these recipients in practice (Brown et al. 2014). The Australian 'Whistling While They Work' (WWTW) study is one of the very few examples in which valuable insight into the role of external recipients is presented. Based on an analysis of a number of different agencies, like ombudsmen, auditor generals, and public service commissions, Annakin (2011) found that the common approach of these agencies to not investigate the wrongdoing independently, but instead referring it back to the whistleblower's own department (similar to the approach in citizen complaint investigations), decreases the effectiveness of these agencies in stopping the wrongdoing or indeed forcing organizations to start detoxing their organizational cultures (see Van Rooij \& Fine, THIS ISSUE). Moreover, this practice leads to the identity of the whistleblower-who often wants to remain anonymous-being revealed within his or her organization. Other problems include the lack of expertise and skills of staff in dealing with whistleblowing cases, and the lack of coordination between the various external recipients, resulting in agencies shoving responsibility onto others.

Given the rather little empirical data available for external recipients-compared to internal recipients-Moberly (2014, p. 295) calls for more research to "better understand the role external recipients can play in the whistleblowing process", not only in investigating wrongdoing, but also in protecting whistleblowers. Likewise, Brown and colleagues (Brown et al. 2014, pp. 489-90) express "the strong need for the study of whistleblowing protection efforts to shift beyond comparative legal 
studies or attempts to identify good and bad features of whistleblowing laws and procedures, in the abstract, to also include [... ] data on how the systems established under those laws are operating in practice". Although this study does not go as far as examining whether whistleblower concerns are effectively resolved by external agencies, as further suggested by Moberly (2014), this paper will provide a descriptive analytic comparison of the various roles whistleblowing agencies have in the studied countries, which is a first step towards bringing these agencies (and not just the legislations) to the forefront, and providing insights into their role in whistleblowing protection. In this sense, the current study is a first step to broadening the disciplinary lens on whistleblowing institutions beyond legal scholarship towards cross-disciplinary study, similar to what Perwati (THIS ISSUE) argues for in the context of corruption. This study more precisely aims to address a gap in the literature by analyzing the role of whistleblowing agencies in 11 countries, focusing on their advisory, psychosocial care, investigative, and preventive tasks. The central research question is: "What are the most important similarities and differences between whistleblowing agencies that perform advisory, psychosocial care, investigative, and/or preventive tasks?" Based on the experiences in these whistleblowing agencies, we will also identify the dilemmas and challenges that the installation of these agencies bring about, in addition to the lessons that can be drawn from that.

By answering this question, the current paper not only commences to fill a research gap; its contribution is also of practical importance. The driving question for policy makers is no longer whether whistleblowing legislation is needed, nor what key aspects such legislation must encompass (Devine 2015, 2016). Rather, the growing number of countries with whistleblowing legislation suggests that the emerging policy question for the next decade will be through what institutional framework whistleblowing legislation can best be implemented (Council of Europe 2014; European Commission 2018). Our paper lays the groundwork for further research to answer this policy implementation question, by presenting a comparative study of external recipients of concerns that provide services to whistleblowers in different countries.

In the next section, this paper will describe the research design, sampling of the cases, data collection methods, and analysis. Then, the main findings will be discussed, which respectively relate to the legal framework, the existence of government agencies and/or NGOs that support whistleblowers, investigative tasks of governmental whistleblowing agencies and NGOs (focusing on wrongdoing and retaliation investigations), ways in which governmental whistleblowing agencies and NGOs provide psychosocial care and advice for whistleblowers, and to what extent such agencies invest in the prevention of wrongdoing. The final part concludes the paper with a discussion and recommendations for future research.

\section{Methods}

This paper reports the results of a comparative study of whistleblowing agencies in 11 different countries that was conducted in the period of June 2017 to February 2018. The research was carried out as part of a broader project (Loyens and Vandekerckhove 2018) commissioned by the Dutch Whistleblowing Authority ('Huis voor klokkenluiders'), established in July 2016. The sampling was carried out at the country level. By means of a purposeful maximum variation sampling technique (Patton 1990), we started with a selection of countries within the Council of Europe and G20 with designated whistleblowing legislation and with institutions that have a certain level of comparability with the Dutch Whistleblowing Authority (being the commissioner of this study), mainly shown in the combination of advisory, psychosocial, investigative, and/or preventive tasks. Given that the Dutch Whistleblowing Authority is an external recipient of disclosures, we focused on those institutions. We aimed for a mix of early-movers and late-movers to include both countries with established institutional frameworks around whistleblowing and countries that are undergoing institutional rearrangements. During the study, some countries on our initial list were omitted (Slovakia and Sweden, respectively because of non-cooperation with key stakeholders and perceived lack of implementation of the law). We later added Australia and Israel, mainly because of their recent 
efforts to further develop the institutional framework to implement the whistleblowing legislation. This resulted in the final sample shown in Table 1 below.

Table 1. Final sample of countries included in this study.

\begin{tabular}{lc}
\hline \multicolumn{1}{c}{ Country } & Whistleblowing Legislation Dates \\
\hline Council of Europe countries & $1998(2013)$ \\
UK & $2004 ; 2013$ \\
Belgium & $2004 ; 2016$ \\
France & 2007 \\
Norway & 2014 \\
Serbia & 2014 \\
Ireland & 2016 \\
The Netherlands & \\
\hline G20, but not CoE countries & $1978(2012) ; 2010$ \\
USA & $2001(2014) ; 2011(2015)$ \\
Republic of Korea & $2004 ; 2009 ; 2013$ \\
Australia & $1997 ; 2008$ \\
\hline Other countries & \\
Israel &
\end{tabular}

Within these countries, we studied both government agencies and NGOs that perform advisory, psychosocial care, investigative, and/or preventive tasks concerning whistleblowing. Data collection methods included: (1) analysis of policy and legislative documents concerning whistleblowing in the selected countries; ${ }^{1}$ (2) analysis of existing research reports about agencies within the selected countries and implementation of whistleblowing legislation; and (3) 21 semi-structured interviews (17 by telephone and four face-to-face) with whistleblowing professionals, being high ranking officers working in the studied agencies, and academic experts who study whistleblowing in their country and who have been involved in recent legislative or institutional rearrangements. An interview protocol was used during the interviews (consisting topics like tasks, institutional arrangements, whistleblower protection, and implementation challenges), while remaining open for additional topics that interviewees considered relevant to discuss. Given the sensitive topic and to avoid social desirability bias, confidentiality of the respondents' identity was guaranteed and interviews were not recorded. During the interviews notes were made, which were written out in full detail shortly after the interview. Data were collected by two researchers who had regular discussions to increase the comparability of data collection. Data analysis was done by first summarizing the data per country in Excel tables and structuring them in general categories like 'institutional characteristics' and 'tasks' (further subdivided in 'advice', 'psychosocial care', 'investigation', and 'prevention'). The findings were then visualized in infographics (as shown in Figures 1 and 2 below), after which a comparison was made between agencies in the selected countries. To increase the validity of the findings, the interviewees reviewed the country summaries and infographics (as a form of member-checking), and their suggested revisions were taken into account. These revisions mainly consisted of providing further detail, and correcting omissions on our part.

\section{Findings}

This part will start with a brief comparison of the whistleblowing legislation in the selected countries, which (although not the focus of this paper) is the framework within which the studied external recipients of whistleblowing concerns operate. The following four sections will discuss the main findings of this study, along the lines of four subthemes. First, while there is a clear

1 In the federal countries in our study, we focused on agencies at the state level, and only included regional agencies if interviewees referred to important differences between state and regional arrangements. 
trend to install governmental whistleblowing agencies that deal with individual whistleblowing cases, this is more common for public sector than private sector whistleblowing. In countries with no or weak governmental whistleblowing agencies or with a fragmented institutional landscape, NGOs sometimes step in to provide whistleblowing protection. Second, we find that, in most countries, the investigation of alleged wrongdoing and the investigation of alleged retaliation are done by separate agencies to avoid conflict of interest, because the investigation of wrongdoing is considered to require more neutrality towards the whistleblower than retaliation investigations. Nevertheless, some whistleblowing agencies combine both investigative tasks. Third, only in a few of the selected countries are government funds available to provide specific psychosocial support for whistleblowers. While most whistleblowing agencies advise whistleblowers about the procedure and the decision to report, only the Dutch Whistleblowing Authority gives continuing support through the entire procedure, not unlike whistleblower protection by NGOs in some of the studied countries. Fourth, most whistleblowing agencies invest in the prevention of wrongdoing in public and/or private sector organizations, but only a few of them have the ambition to perform as a center for knowledge and expertise. The main findings are summarized in Table 2.

\subsection{Legal Framework in Selected Countries}

When comparing whistleblowing arrangements in the selected countries, two important differences can be observed, respectively relating to the sectoral scope of the legislation and the type of wrongdoing for which the legislation offers protection if reported by whistleblowers. With regard to sectoral scope, whilst some countries have separate whistleblowing regulations for the public and private sector (Australia, Israel, the Republic of Korea, and the USA) or whistleblowing provisions that only cover the public sector (Belgium), there is a clear trend to install stand-alone whistleblowing legislation covering both public and private sectors (Ireland, France, The Netherlands, Serbia, Norway, and the UK). Federal countries like the USA and Australia tend to have a fragmented legal framework, with not only separate pieces of whistleblowing legislation for the public and private sector, but also different regulations and agencies at various levels of the public sector. This has, in the USA, resulted in "a patchwork of more than 60 laws in different states, at different levels, for different sectors (including the private sector), and for different purposes" (Loyens and Vandekerckhove 2018, p. 25). The situation in Australia is similar (albeit with a lower number of whistleblowing laws), but discussions about unifying the legislation to cover both the public and the private sector are ongoing. Recently, Ireland and France made the shift from fragmented whistleblower protection towards a unified stand-alone legislation, which has the advantage that protection measures and whistleblowing statutes are the same for both public and private sector whistleblowers (Loyens and Vandekerckhove 2018). 
Table 2. Summary of whistleblowing arrangements concerning external recipients of concerns in 11 countries.

\begin{tabular}{|c|c|c|c|c|c|}
\hline Countries & Sectoral Scope & Whistleblowing Agency & Investigation & Care \& (Legal) Advice & Prevention (Which Agency) \\
\hline Australia & Separate for public and private sector & Government: ombudsman & Wrongdoing or referral & Government: information & Ombudsman (government) \\
\hline Belgium & Only public sector & Government: ombudsman & Wrongdoing and retaliation & Government: information, advice & I \\
\hline Ireland & Public and private sector & Government: prescribed persons & No investigative agency & NGO: advice, legal assistance & Integrity@Work (NGO) \\
\hline Israel & Separate for public and private sector & Government: ombudsman & $\begin{array}{l}\text { Wrongdoing and retaliation in } \\
\text { separate units }\end{array}$ & Government: information, advice & / \\
\hline France & Public and private sector & Government: ombudsman & Retaliation & 1 & I \\
\hline The Netherlands & Public and private sector & $\begin{array}{l}\text { Government: Dutch Whistleblowing } \\
\text { Authority }\end{array}$ & Wrongdoing and retaliation & Government: psychologist, advice & Dutch Whistleblowing Authority (government) \\
\hline Norway & Public and private sector & $\begin{array}{l}\text { Government: clinic (only } \\
\text { psychosocial support) }\end{array}$ & No investigative agency & Government: psychosocial care clinic & / \\
\hline Republic of Korea & Separate for public and private sector & Government: ACRC & Retaliation & NGO: advice, legal assistance & I \\
\hline Serbia & Public and private sector & NGO: Pistaljka & $\begin{array}{l}\text { Only investigative } \\
\text { journalists (Pistaljka) }\end{array}$ & NGO: advice, legal assistance & Pistaljka (NGO) \\
\hline UK & Public and private sector & $\begin{array}{l}\text { Government: prescribed persons \& } \\
\text { National Guardian Office (NHS) }\end{array}$ & No investigative agency & NGO: advice, legal assistance & NHS (government); Public Concern at Work (NGO) \\
\hline USA & Separate for public and private sector & $\begin{array}{l}\text { Government: OSC, SEC, OWB, } \\
\text { MSPB; NGO: GAP }\end{array}$ & $\begin{array}{l}\text { Retaliation (OSC, MSPB) \& } \\
\text { wrongdoing in separate units (SEC); } \\
\text { investigative journalists (GAP) }\end{array}$ & Government: information, advice (OWB) & OSC (government); GAP (NGO) \\
\hline
\end{tabular}


When comparing the type of wrongdoing for which whistleblowers receive protection if they report it, we find much variation in the wording and definitions used in the selected countries. Despite the differences, we can observe some patterns. First, most legislation covers all of the following types of wrongdoing: (1) breaches of law, (2) danger to the health and safety of people, and to the environment, and (3) integrity violations. In the third type, there is huge variation in the wording and scope. Some examples include: 'shortcoming of public service duty' (Belgium), 'abuse of public trust' (Australia), 'abuse of authority' (Republic of Korea, USA), 'breaches of ethical codes' (Norway), 'gross mismanagement' (Ireland, USA), and 'violation of administration' (Israel). Moreover, this category is omitted in the whistleblowing legislation in France and the UK. Some countries add other types of wrongdoing to broaden the scope of the legislation. Norway stands out by also including "negative culture, corruption, illegality and unethical or harmful incidents" (Lewis and Trygstad 2009, p. 382). A noteworthy observation is that the scope of wrongdoing in private sector legislation tends to be less broad than the scope in public sector legislation (see e.g., Australia and USA), although the Republic of Korea is a possible exception. Only in a few countries does the legislation explicitly state that the wrongdoing should be in the public interest. In 2013, a 'public interest test' was introduced in the UK: a judge at an Employment Tribunal hearing considers whether the whistleblower had 'a reasonable belief the disclosure was in the public interest'. Given the very broad and imprecise definition of wrongdoing in the Norwegian whistleblowing law (see above), the legislative committee that will suggest revisions to the law is considering introducing a public interest test as well. Although in the Netherlands no public interest test is installed, the Dutch law explicitly stipulates that whistleblowers can only be protected if they report wrongdoing that may harm the public interest.

Of course, in all countries, whistleblowing legislation makes it possible for whistleblowers to make claims in court with regard to the wrongdoing they have observed and retaliation they have experienced. How these courts function is, however, outside of the scope of our research. In this paper, we concern ourselves with organisations other than courts that may facilitate successful whistleblowing (i.e., effective in stopping wrongdoing and safe for the whistleblower).

\subsection{Governmental Whistleblowing Agencies and NGOs}

Particularly in countries with separate whistleblowing legislation for the public sector, there is a trend to install governmental whistleblowing agencies that advise or support whistleblowers, investigate alleged wrongdoing and/or alleged retaliation, offer protection, and promote the prevention of wrongdoing. In our study, six countries have already installed such an agency, ${ }^{2}$ but the combination of tasks differs (as shown in Figure 1). In four of the selected countries, this role is mandated to the Ombudsman (Australia, ${ }^{3}$ Belgium, ${ }^{4}$ Israel, and France). In the USA, the Office of Special Counsel (OSC) is the authorized whistleblowing agency for the public sector. Other whistleblowing agencies, such as the Securities and Exchange Commission (SEC) that implements the Dodd-Frank Act, offer protection for all whistleblowers who report security law violations. Within the SEC, the Office of the Whistleblower $(\mathrm{OWB})$ investigates alleged retaliation, gives advice to whistleblowers, and promotes the prevention of wrongdoing. So far, only in the Republic of Korea and the Netherlands is a government agency installed to deal with both public and private sector whistleblowers. Since its establishment in 2001, the mandate of the Anti-Corruption and Civil Rights Commission (ACRC) in the Republic of Korea has grown from dealing with anti-corruption to dealing with whistleblowing cases on a broader range of wrongdoing in the public and private sector (covered by two separate pieces of legislation).

2 In France, the new legislation had mandated the ombudsman for the investigation of whistleblowing cases, but the executive decree implementing these new tasks for the ombudsperson had not been signed at the time of writing this paper (June 2018). Therefore, France is not included in Figure 1.

3 As for Australia, this study focused on the Commonwealth Ombudsman at the national level.

4 As for Belgium, this study focused on the Flemish and Federal level. At both levels, the Ombudsman operates as the whistleblowing agency for the public sector. 
Hence, only the Netherlands has a governmental whistleblowing agency that operates under a stand-alone whistleblowing legislation for both the public and the private sector. Other countries in our sample are exploring the same option (France, Norway, and Australia).

Although the UK has the longest experience of a whistleblowing law that covers the public and private sector, it does not have a central whistleblowing agency linked to that law, which is also the case in Ireland. The legislations in both of these countries only provide a list of 'prescribed persons' that receive reports and investigate alleged wrongdoing. For Ireland, there is no information available as to how pro-active these regulating bodies are concerning whistleblowing cases. But in the UK, the National Audit Office recently conducted an audit (in 2015) that showed that staff within these 'prescribed person' bodies were often unaware that they were mandated as a recipient of whistleblower concerns. Specifically for the National Health Service (NHS) in the UK, a whistleblowing agency was established in 2016 (see below).

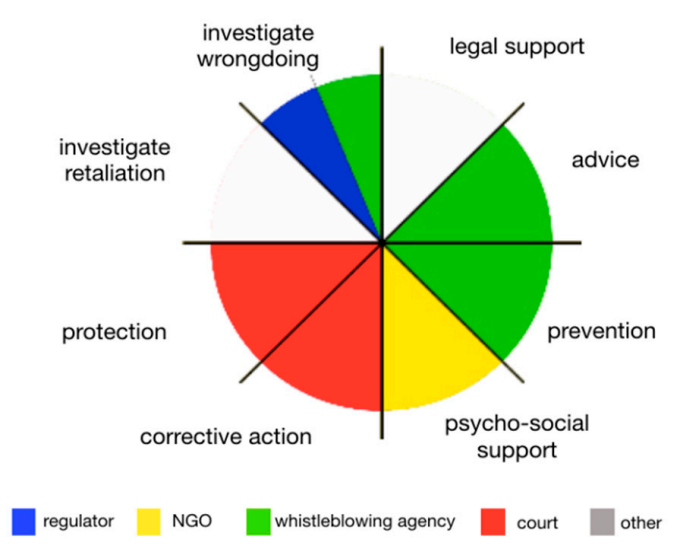

Australia

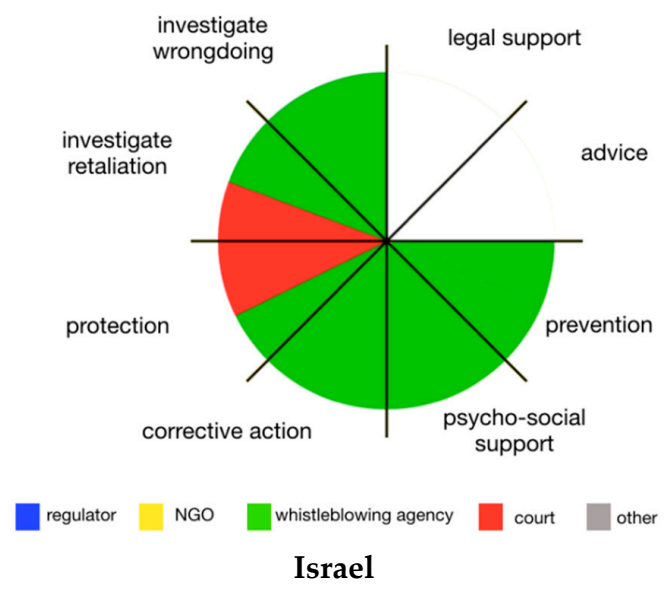

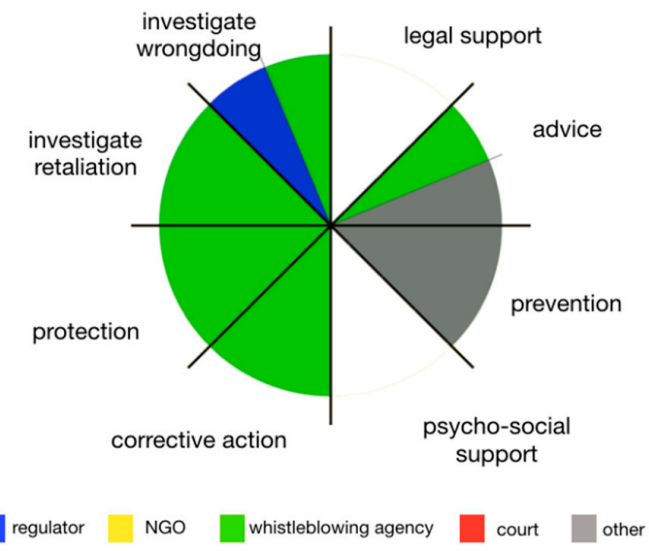

Belgium

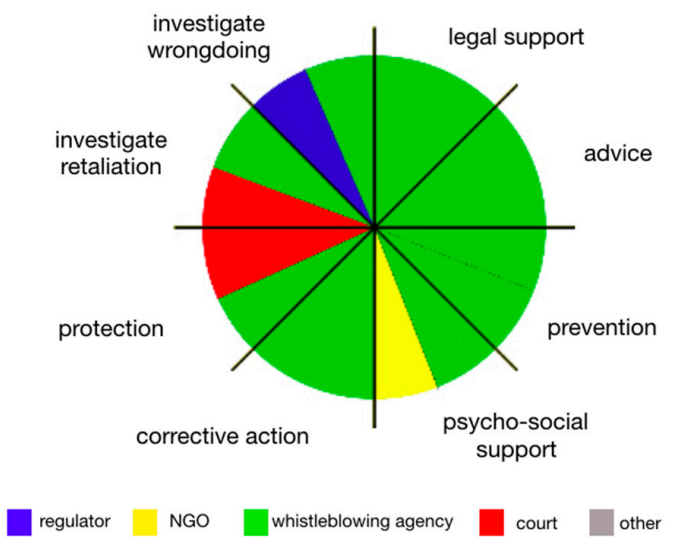

the Netherlands

Figure 1. Cont. 

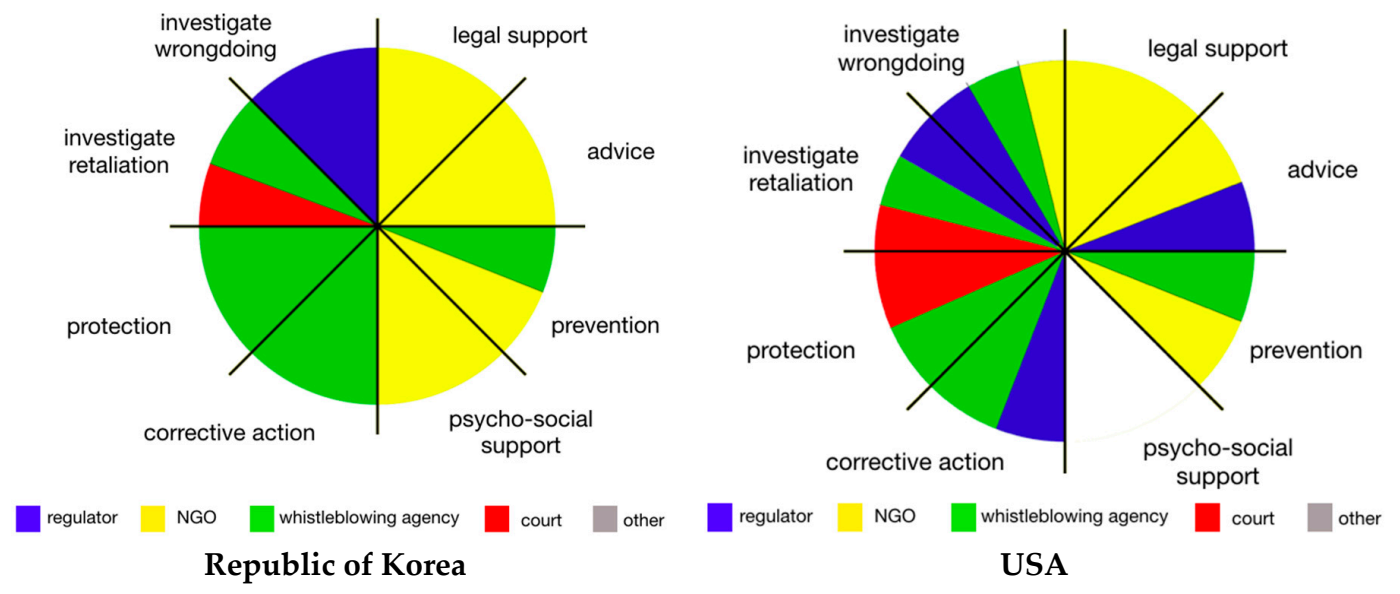

Figure 1. Various tasks of governmental whistleblowing agencies in this study.

In some countries, specific NGOs have been created that conduct some of the tasks of the governmental whistleblowing agencies described above. Sometimes the role of NGOs is complementary to that of governmental whistleblowing agencies (like the Government Accountability Project $\left(\mathrm{GAP}^{5}\right)$ in the USA), while in other countries, these NGOSs have stepped in because no government agency has been installed (yet) (like Pistaljka ${ }^{6}$ or 'The Whistle' in Serbia) (see Figure 2).

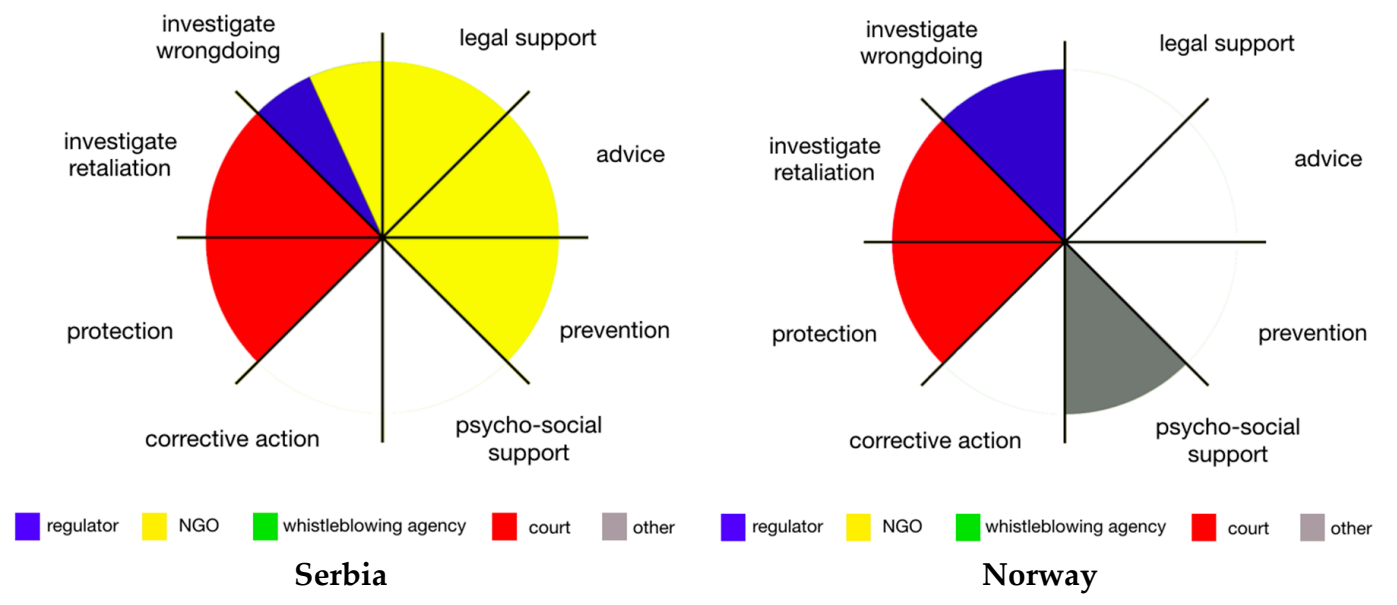

Figure 2. Agencies involved in whistleblowing in Serbia and Norway.

Particularly in countries without either a governmental whistleblowing agency or NGOs that support whistleblowers (as in Norway, see Figure 2), whistleblowers find themselves in a precarious situation, as has been shown in research of the Fafo Institute of Labour and Social Research in Oslo. The researchers of Fafo conclude that since 2010, whistleblowing has become more difficult in Norway: in surveys, whistleblowers increasingly report being retaliated against, resulting in a decrease of the willingness to report (Bjørkelo 2017; Fafo 2016), and qualitative studies show negative consequences of whistleblowing like "job loss [and] the stigma of association of even being seen as a friend or an associate of a current or previous employee that has reported about wrongdoing at work" (Bjørkelo 2017, p. 8). An interviewee states that the situation seems particularly problematic in the Norwegian public sector, but research to support that statement has yet to be conducted.

5 See: https://www.whistleblower.org/.

6 See: https://pistaljka.rs/. 


\subsection{The Investigation of Reported Wrongdoing and Alleged Retaliation}

Most whistleblowing agencies in our sample either investigate reported wrongdoing (Australia), or alleged retaliation (France, USA OSC, USA Merit Systems Protection Board (MSPB), Republic of Korea). However, how these agencies operate in practice has not remained uncriticized. The Merit Systems Protection Board (MSPB), for example, which is a court-like government agency to which federal whistleblowers in the USA can appeal with retaliation claims (or because they believe to have experienced other Prohibited Personnel Practices), has received severe criticisms from GAP (Devine 2017) and some of our interviewees. Several whistleblowing experts in our study explain that the administrative judges in general have a hostile attitude towards the whistleblowing legislation, which may explain the $95-98 \%$ rulings against whistleblowers, and are prone to informal political pressure, which reduces their (perceived) independence in practice. Their lack of expertise in dealing with whistleblowing cases in practice is also mentioned in several interviews, as are the delays that result in final decisions only being made after three to six years. Combined, these factors negatively influence the already vulnerable position of whistleblowers within the American federal government. As for Australia, our study confirms the finding of Annakin (2011) that in practice, the Ombudsman often does not investigate the disclosed wrongdoing, but refers it to the department of the whistleblower for investigation. The Ombudsman must be informed by these agencies of decisions not to investigate and may extend time limits for such investigations. ${ }^{7}$ On its own current interpretation of the legislation, the Ombudsman cannot investigate retaliation against whistleblowers. However, some experts and whistleblowers think the Ombudsman can, which illustrates the lack of clarity of the current legislation. In practice, the Ombudsman thus only investigates whether agencies applied the procedural requirements of the whistleblowing legislation in dealing with the disclosure. If the Ombudsman concludes that an agency has erred, recommendations are made and reported to the Prime Minister and to the Parliament if the department decides not to implement them. Given the risks of the decentralized investigative approach in which "the Principal Officer and Authorised Officer within each agency [are held] responsible for receiving, assessing, allocating, investigating and responding to each disclosure" (Moss 2016, p. 26) and the lack of experience of the Commonwealth Ombudsman in employer-employee disputes, it has been suggested that whistleblowing protection be taken away from the Commonwealth Ombudsman and moved to a new Whistleblower Protection Authority (Moss 2016; Parliamentary Joint Committee on Corporations and Financial Services 2017).

In some countries, the governmental whistleblowing agencies investigate both the alleged wrongdoing and retaliation claims (Belgium, Israel, The Netherlands, SEC USA). For the Israeli Ombudsman $^{8}$ and the SEC (USA), these tasks are performed by separate departments within the same agency. Interviewees could not always give clear reasons as to why these investigative tasks are separated. Some referred to the different types of expertise needed for both types of investigations, or the risk of conflicting interests because investigating wrongdoing may require more neutrality towards the whistleblower than retaliation investigations. In departments combining both investigative tasks, there is (in their opinion) an increased risk of partiality in wrongdoing investigations. Only in Belgium (for the public sector) and the Netherlands (for public and private sector) are investigations of wrongdoing and retaliation done within the same department. However, because in Israel no 'Chinese walls' are installed between both investigative departments, resulting in elaborate and easy information sharing that is not regulated with protocols, we see no substantial difference from the Belgian and Dutch situation. Interviewees in these countries explained that combining these investigative tasks

7 In 2016-2017, 684 disclosures were made to all Commonwealth agencies, of which only 60 were made directly to Ombudsman. Of these 60 disclosures, only 40 PID's were accepted and 23 of those were referred to the Agency concerned to be investigated. Furthermore, the Ombudsman received 34 complaints about how PID's were dealt with in agencies, and finalized 44 complaint investigations (Commonwealth Ombudsman 2017).

8 In Israel, the State Comptroller investigates the alleged wrongdoing, and the Ombudsman investigates retaliation against whistleblowers and provides protection. The Ombudsman is part of the State Comptroller in Israel. 
(or exchanging information about it) is advisable, because the issues that are investigated cannot be easily separated in practice.

Some NGOs also have a role in the investigation of wrongdoing, but obviously their (perceived) independence in practice is different than that of governmental whistleblowing agencies. Both GAP (USA) and Pistaljka (Serbia) employ journalists who investigate the charges whistleblowers make and publish the results in articles and reports. By doing so, these organisations help to expose wrongdoing in the government and other agencies to the public. Unlike some governmental whistleblowing agencies (see above), these NGOs do not investigate alleged retaliation against whistleblowers.

\subsection{Psychosocial Care and Advice to Whistleblowers}

In our sample, government funds for specific psychosocial care for whistleblowers are only available in the Netherlands and in Norway. In Norway, a psychosocial care clinic was established in 2012-funded by the Ministry of Health — for whistleblowers who have suffered retaliation. More than 200 whistleblowers have already been given psychosocial care in the past six years. Nevertheless, the program will probably be closed down. The official reason is money-related, but an interviewee explains that an additional reason may be that the government feels uncomfortable having such a clinic, given that it may be perceived as a symptom of a culture that is against whistleblowers and freedom of speech. The Dutch Whistleblowing Authority provides free psychological care (by one psychologist), which the Israeli Ombudsman is also starting up as part of the development of a more holistic approach to whistleblower protection. While in some other countries (Australia, UK, Republic of Korea), civil society organizations have stepped in to fill that need, whistleblowers in most of the studied countries are referred to general employee assistance programs that are installed to support employees with various kinds of psychosocial needs, like stress and the consequences of harassment or bullying. Some interviewees claim that these programs often cannot meet the particular needs of whistleblowers who have experienced retaliation.

Most governmental whistleblowing agencies in our study provide information to whistleblowers about the procedure (Australia, Belgium, the Netherlands, Israel, OWB in USA) and/or give advice to would-be whistleblowers about their decision to report (Belgium, Israel, the Netherlands, OWB in USA). The OWB of the American SEC, for example, operates a hotline where (would-be) whistleblowers, their attorneys, and other citizens can ask information about the program (e.g., eligibility criteria for awards, confidentiality guarantees, investigative procedure and the appropriateness of the SEC to handle a specific tip, see SEC 2017). Whereas in Israel advice to whistleblowers is not formally a task of the Ombudsman or the State Comptroller, these agencies do inform whistleblowers about the risks of whistleblowing and available reporting channels. Only the Dutch Whistleblowing Authority offers more comprehensive advice. Whistleblowers are given continuous support throughout the entire investigation, for example, in the form of assistance before and during the investigation (including practical help like writing letters to employers) and legal advice during the entire procedure (but not representation in court). This approach is similar to the support and assistance given by some NGOs (Ireland, Republic of Korea, UK, USA and Serbia), although these often also provide legal counselling and representation in court.

\subsection{Whistleblowing Agencies and the Prevention of Wrongdoing}

Most governmental whistleblowing agencies in our study (Australia, The Netherlands, Republic of Korea, UK, and USA) invest in the prevention of wrongdoing, but the scope of this prevention task differs. Probably at the forefront is the recently established National Guardian Office in the UK, which performs 'speak-up culture audits' of health care organisations and publishes the results thereof in culture review reports (that include recommendations and requirements with a set deadline). In other countries, such a watchdog-like approach is only taken by civil society organisations. The National Guardian Office also provides awareness raising and training, and supports inter-vision between Guardians at Hospital Trust level. In the other four countries, the prevention tasks are not as 
comprehensive as those of the NHS Guardian. Some whistleblowing agencies train other agencies (e.g., Office of Special Counsel in USA) or public officials (e.g., Australian Ombudsman) on how to implement the whistleblowing legislation. The Dutch Whistleblowing Authority goes a step further by also assisting employers with implementing whistleblowing policy. Moreover, this agency has the ambition to operate as a center of knowledge and expertise for whistleblowing policy and integrity management. Some NGOs, like GAP (USA) and Pistaljka (Serbia), also operate as a knowledge center concerning whistleblowing policy and provide ad hoc advice to employers with questions about whistleblowing legislation. In addition, these NGOs, like Integrity@Work (Ireland) and Public Concern at Work (UK), provide training for agencies (and in the case of Serbia, also judges) involved in whistleblowing protection or investigation.

\section{Discussion and Conclusions}

We agree with Moberly (2014) that external recipients of whistleblower disclosures are under-studied. Most whistleblowing studies have focused on whistleblowing legislation and the whistleblower: "what makes them report, what they report, how many and how often whistleblowers come forward, and what happens to them" (Lewis et al. 2014, p. 19). While our study did not analyze the effectiveness of external whistleblowing agencies in dealing with whistleblower concerns (Moberly 2014), it lays the groundwork from which further in-depth research can be conducted with reference to the actual role of the recipients in enhancing whistleblowing protection. Our study particularly aimed to gain a greater understanding of the various roles and tasks that external recipients of disclosed concerns (both government agencies and NGOs) have in various countries with whistleblowing legislation. In this study, we have seen two emerging trends concerning whistleblowing protection. First, countries are increasingly installing stand-alone whistleblowing legislations covering both public and private sectors. Whilst stand-alone whistleblowing legislation in itself is not new (Brown et al. 2014; Vandekerckhove 2010), what is new is that one piece of legislation covers both public and private sector whistleblowing. This approach seems, however, to have been more difficult for federal countries (like Australia, Belgium, and USA), which often have a fragmented legislative framework with a variety of whistleblowing statutes at different government levels, and sometimes (in Australia, USA) one or more separate whistleblowing laws for the private sector. On the one hand, this approach lacks coherence and may be confusing for whistleblowers. On the other hand, as one of our interviewees confirmed, one advantage of a fragmented legal framework is that whistleblowers often have different agencies they can go to in the case of reprisal; they thus have different options to seek relief. It remains unclear why a unified legal framework does not necessarily create a more centralized institutional framework. The UK and Ireland are key countries to study this further. Both these countries have a unified whistleblowing legislation, yet a fragmented institutional framework. This institutional framework continues to change, however, with a number of 'new comers' such as Integrity@Work in Ireland, and WhistleblowersUK and the National Guardian Office in the UK. It was clear in our study that institutional actors in all countries were seeking to learn from the Dutch and French institutional experiments with centralized and holistic government agencies.

Second, there is a clear trend to install governmental whistleblowing agencies to implement whistleblowing legislation. The majority of the studied countries already have one or more of these agencies, which often have several tasks in whistleblowing protection. However, the precise combination of tasks differs between the studied countries. The Netherlands stands out with a combination of advisory, preventive, and twofold investigative tasks (wrongdoing and retaliation claims) and psychosocial care in one agency. However, this agency, established in 2016, received severe criticism and negative media attention, because in 2016 and 2017 no investigation had been completed (see, e.g., Rengers 2017; Voskuil 2017). The next years will show whether the agency will be able to make a new start implementing the recommendations of a recent internal 
investigation (Ruys 2017). The Israeli Ombudsman ${ }^{9}$ and the SEC (USA) ${ }^{10}$ each combine four of the five tasks of the Dutch Whistleblowing Authority. It seems that the importance of a holistic approach in whistleblowing protection is increasingly emphasized. More and more whistleblowing agencies recognize that whistleblowing protection is not only about responding to retaliation claims of whistleblowers, but also about investigating and trying to stop the wrongdoing, as well as advising would-be whistleblowers about their decision to report. However, research on the effectiveness of less or more holistic ways in which external recipients deal with whistleblower disclosures is lacking (Lewis et al. 2014; Vandekerckhove et al. 2014). More insight is also needed into how easily these tasks can be combined within the same agency or even the same department, and the possible positive or negative effects of such attempts. To what extent is there, for example, a conflict of interest when investigations of wrongdoing and retaliation are combined, and if so, which safeguards are needed to avoid partial investigations? How do advice to (would-be) whistleblowers and an independent investigation of disclosed wrongdoing go together? And what are the consequences of (not) installing 'Chinese walls' between any of these functions?

Despite the trend towards a more holistic approach, our study has also shown that not many countries provide funds for specific psychosocial support adapted to the needs of whistleblowers who have suffered from retaliation. Only the Netherlands and Norway have installed such care and Israel is starting it up. In other countries, whistleblowers who need psychosocial support are referred to general employee assistance systems. Research on the effectiveness of either of these systems is, however, lacking. Previous studies have shown that retaliation is a common (but varying) risk for whistleblowers, and that this may result in various types of 'suffering', such as work-related problems (e.g., demotivation, disengagement, and distrust to coworkers) (Smith 2014) and psychological problems (van der Velden et al. 2018) like "anxiety, depression, irritability or dread, even suicidal thoughts" (Hedin and Månsson 2012, p. 162). However, more research is needed to determine which whistleblowers suffer and how they suffer (particularly outside the USA where most research is conducted) (Smith 2014). Moreover, scholars should also analyze how those who have experienced reprisals have overcome the consequences of it and which support mechanisms are helpful. Such research would be useful for the debate on whether governments should invest in specific tailor-made psychosocial support for whistleblowers or refer those who suffer from retaliation to general employee assistance programs.

Finally, our study shows that a lack of expertise among those who need to implement whistleblowing legislation strongly weakens the position of the whistleblower, as seen in the Australian Commonwealth Ombudsman and the MSPB (USA). This confirms the finding in the Australian WWTW study (Annakin 2011) that insufficient skills of staff results in unsatisfactory assessment and response to whistleblowing disclosures. Therefore, it seems promising that some governmental whistleblowing agencies (e.g., NHS in UK and Australian Ombudsman) and NGOs invest in the training of government officials involved in the implementation of the legislation (e.g., GAP, Integrity@Work, Public Concern at Work) or judges who enforce whistleblowing protection (e.g., Pistaljka). Moberly (2014), referring to Miceli et al. (2009), in the same line argues that recipients of concerns should receive training to deal with whistleblower disclosures, but that research on the effects of such trainings is needed.

In conclusion, this paper aimed to increase our understanding of the role of external recipients of whistleblowing concerns in practice and calls for more such research. This study, however, had some limitations that should be taken into account in further research. First, given time and budget constraints, we were only able to conduct a limited number of interviews in each of the selected

9 The Israeli Ombudsman (1) investigates wrongdoing reported by whistleblowers, (2) investigates alleged retaliation against whistleblowers, (3) provides psychosocial support to whistleblowers, and (4) performs prevention tasks in terms of awareness raising via information dissemination campaigns.

10 The SEC combines following tasks: (1) advice to whistleblowers, (2) investigation of alleged wrongdoing, (3) investigation of alleged retaliation, and (4) prevention. 
countries. This limitation was to some extent overcome by consulting many documents and reports which offered rich data on the practice of whistleblowing protection. Moreover, the interviewees were all experts on this topic and therefore able to critically assess both the validity of the written information, and strengths and weaknesses of whistleblowing protection in their country. Further research could try to get in contact with more key stakeholders within the studied agencies to gain in-depth knowledge of how they operate in practice. Particularly in countries with limited written information in English (e.g., Norway and Serbia) and data collection by researchers who do not speak the respective languages, thus relying more on interview data, it is advisable to include more interviewees in the study. Second, given the focus on the comparison of differences and similarities between countries, this study can only give an overview of trends and challenges. More detailed case studies should be conducted to further unravel institutional practices and mechanisms of whistleblowing protection in the respective countries, particularly outside USA and UK context, which have already been studied extensively. Third, this study only reports on whistleblowing arrangements in 11 countries. Given the importance of national, legislative, and cultural context for whistleblowing protection, the findings cannot be generalized to countries not included in this study. Nevertheless, given the diversity of countries in the sample (which was deliberately aimed for at the outset of the study), the conclusions could offer useful insights for whistleblowing arrangements in other countries.

Author Contributions: Conceptualization, K.L. and W.V.; Methodology, K.L. and W.V.; Validation, K.L. and W.V.; Formal Analysis, K.L. and W.V.; Investigation, K.L. and W.V.; Resources, K.L. and W.V.; Writing-Original Draft Preparation, K.L. and W.V.; Writing-Review \& Editing, K.L. and W.V.; Visualization, W.V.; Supervision, K.L.; Project Administration, K.L.; Funding Acquisition, K.L.

Funding: This research was funded by the Dutch Whistleblowing Authority.

Conflicts of Interest: The authors declare no conflicts of interest.

\section{References}

Annakin, Lindy. 2011. In the Public Interest or Out of Desperation? The Experience of Australian Whistleblowers Reporting to Accountability Agencies. Unpublished Ph.D. thesis, University of Sydney, Sydney, Australia. Available online: https://ses.library.usyd.edu.au/bitstream/2123/7904/1/1_annakin_ 2011_thesis.pdf (accessed on 22 June 2018).

Ayers, Susan, and Steven E. Kaplan. 2005. Wrongdoing by consultants: An examination of employees' reporting intentions. Journal of Business Ethics 57: 121-37. [CrossRef]

Bjørkelo, Brita. 2017. Norwegian whistleblowing research: A case of Nordic exceptionalism? In Selected Papers from the International Whistleblowing Research Network Conference. Edited by David Lewis and Wim Vandekerckhove. London: International Whistleblowing Research Network, pp. 6-17.

BluePrint for Free Speech. 2015. Breaking the Silence. Strengths E Weaknesses in G20 Whistleblower Protection Laws. Melbourne: BluePrint for Free Speech.

Bosua, Rachelle, Simon Milton, Suelette Dreyfus, and Reeva Lederman. 2014. Going public: Researching external whistleblowing in a new media age. In International Handbook on Whistleblowing Research. Edited by Alexander Jonathan Brown, David Lewis, Richard E. Moberly and Wim Vandekerckhove. Cheltenham: Edward Elgar Publishing, pp. 250-72.

Brown, A. J., Daniel P. Meyer, Chris Wheeler, and Jason Zuckerman. 2014. Whistleblower Support in Practice: Towards an Integrated Research Model. In International Handbook on Whistleblowing Research. Edited by A. J. Brown, David Lewis, Richard E. Moberly and Wim Vandekerckhove. Cheltenham: Edward Elgar Publishing, pp. 457-94.

Commonwealth Ombudsman. 2017. Annual Report 2016-2017. Canberra: Commonwealth Ombudsman.

Council of Europe. 2014. Recommendation CM/Rec(2014)7 of the Committee of Ministers to Member States on the Protection of Whistleblowers. Strasbourg: Council of Europe.

De Graaf, Gjalt. 2010. A report on reporting: Why peers report integrity and law violations in public organizations. Public Administration Review 70: 767-79. [CrossRef] 
Devine, Tom. 2015. International best practices for whistleblower statutes. In Developments in Whistleblowing Research. Edited by David Lewis and Wim Vandekerckhove. London: International Whistleblowing Research Network, pp. 7-19.

Devine, Tom. 2016. International best practices for whistleblowing policies. In Checkmate to Corruption: Making the Case for a Wide-Ranging Initiative on Whistleblower Protection. Edited by Wim Vandekerckhove. Geneva: Public Services International, pp. 23-26.

Devine, Tom. 2017. Corrected testimony of Thomas Devine. Government Accountability Project before the House Oversight and Government Reform Committee, Subcommittee on Federal Workforce, U.S. Postal Service and the Census on Whistleblower Protection since Passage of the Whistleblower Protection Enhancement Act. Washington: U.S. Government Publishing Office.

Dworkin, Terry Morehead, and Melissa S. Baucus. 1998. Internal vs. external whistleblowers: A comparison of whistleblowering processes. Journal of Business Ethics 17: 1281-98. [CrossRef]

Dworkin, Terry Morehead, and Arthur J. Brown. 2013. The Money or the Media? Lessons from Contrasting Developments in US and Australian Whistleblowing Laws. Seattle Journal of Social Justice 11: 653-713.

European Commission. 2018. Proposal for a Directive of the European Parliament and of the Council Establishing Common Minimum Standards for the Protection of Persons Reporting on Breaches in Specific Union Policy Areas. Brussels: European Commission, April 23.

Fafo. 2016. Whistleblowing and Freedom of Speech in Norwegian Working Life 2016. English Summary of Varsling og Ytringsfrihet i Norsk Arbeidsliv 2016, Fafo-Rapport 2016. Oslo: Fafo, p. 33.

Fasterling, Björn, and David Lewis. 2014. Leaks, legislation and freedom of speech: How can the law effectively promote public-interest whistleblowing? International Labour Review 153: 71-92. [CrossRef]

Hedin, Ulla-Carin, and Sven-Axel Månsson. 2012. Whistleblowing processes in Swedish public organisations-Complaints and consequences. European Journal of Social Work 15: 151-67. [CrossRef]

Lewis, David, and Sissel Trygstad. 2009. Protecting whistleblowers in Norway and the UK: A case of mix and match? International Journal of Law and Management 51: 374-88. [CrossRef]

Lewis, David, Arthur J. Brown, and Richard Moberly. 2014. Whistleblowing, its importance and the state of the research. In International Handbook on Whistleblowing Research. Edited by Arthur J. Brown, David Lewis, Richard E. Moberly and Wim Vandekerckhove. Cheltenham: Edward Elgar Publishing, pp. 1-34.

Loyens, Kim. 2012. Integrity Secured. Understanding Ethical Decision Making among Street-Level Bureaucrats in the Belgian Labor Inspection and Federal Police. Ph.D. dissertation, Katholieke Universiteit Leuven, Leuven, Belgium.

Loyens, Kim, and Wim Vandekerckhove. 2018. The Dutch Whistleblowing Authority in an International Perspective: A Comparative Study. Utrecht University and University of Greenwich, forthcoming.

Mesmer-Magnus, Jessica R., and Chockalingam Viswesvaran. 2005. Whistleblowing in organizations: An examination of correlates of whistleblowing intentions, actions, and retaliation. Journal of Business Ethics 62: 277-97. [CrossRef]

Miceli, Marcia P., and Janet P. Near. 1992. Blowing the Whistle: The Organizational and Legal Implications for Companies and Employees. New York: Lexington.

Miceli, Marcia P., and Janet P. Near. 2002. What makes whistle-blowers effective? Three field studies. Human Relations 55: 455-79. [CrossRef]

Miceli, Marcia P., Janet P. Near, and Charles R. Schwenk. 1991. Who blows the whistle and why? Industrial and Labor Relations Review 45: 113-30. [CrossRef]

Miceli, Marcia P., Janet Pollex Near, and Terry M. Dworkin. 2008. Whistle-Blowing in Organizations. New York: Routledge.

Miceli, Marcia P., Janet P. Near, and Terry Morehead Dworkin. 2009. A word to the wise: How managers and policy-makers can encourage employees to report wrongdoing. Journal of business ethics 86: 379-96. [CrossRef]

Moberly, Richard. 2014. 'To persons or organizations that may be able to effect action': Whistleblowing recipients. In International Handbook on Whistleblowing Research. Edited by A. J. Brown, David Lewis, Richard E. Moberly and Wim Vandekerckhove. Cheltenham: Edward Elgar Publishing, pp. 273-97.

Morvan, Patrick. 2009. A comparison of the freedom of speech of workers in French and American law. Indiana Law Journal 84: 1015-46.

Moss, Philip. 2016. Review of the Public Interest Disclosure Act 2013. An Independent Statutory Review Conducted by Mr. Philip Moss AM. Canberra: Department of the Prime Minister and Cabinet.

Near, Janet P., and Marcia P. Miceli. 1996. Whistle-blowing: Myth and reality. Journal of Management 22: 507-26. [CrossRef] 
Near, Janet P., Terry Morehead Dworkin, and Marcia P. Miceli. 1993. Explaining the whistle-blowing process: Suggestions from power theory and justice theory. Organization Science 4: 393-411. [CrossRef]

OECD. 2011. Study on Whistleblower Protection. Frameworks, Compendium of Best Practices and Guiding Principles for Legislation. Paris: OECD.

Osterhaus, Anja, and Craig Fagan. 2009. Alternative to Silence: Whistleblower Protection in 10 European Countries. Report for Transparency International, November 15. Available online: https:/ /www.transparency. org/whatwedo/publication/alternative_to_silence_whistleblower_protection_in_10_european_countries (accessed on 22 June 2018).

PACE (Parliamentary Assembly of the Council of Europe). 2009. The Protection of Whistleblowers. Report of the Committee of Legal Affairs and Human Rights, Document 12006. September 14. Available online: http:/ / assembly.coe.int/nw/xml/XRef/Xref-XML2HTML-en.asp?fileid=12302 (accessed on 22 June 2018).

Parliamentary Joint Committee on Corporations and Financial Services. 2017. Whistleblower Protections. Canberra: Parliamentary Joint Committee on Corporations and Financial Services.

Patton, Michael Quinn. 1990. Qualitative Evaluation and Research Methods. Newbury Park: Sage.

Rengers, Merijn. 2017. Crisis in Huis voor Klokkenluiders (Crisis in Dutch House for Whistleblowers). NRC, October 19. Available online: https://www.nrc.nl/nieuws/2017/10/19/crisis-in-huis-voorklokkenluiders-13583268-a1578008 (accessed on 22 June 2018).

Roberts, Peter. 2014. Motivations for whistleblowing: Personal, private and public interests. In International Handbook on Whistleblowing Research. Edited by A. J. Brown, David Lewis, Richard E. Moberly and Wim Vandekerckhove. Cheltenham: Edward Elgar Publishing, pp. 207-29.

Roberts, Peter, and A. J. Brown. 2010. The Australian legislative experience. In A Global Approach to Public Interest Disclosure: What Can We Learn from Existing Whistleblowing Legislation and Research? Edited by David B. Lewis. Cheltenham: Edward Elgar, pp. 56-73.

Rothschild, Joyce, and Terance D. Miethe. 1999. Whistle-blower disclosures and management retaliation. Work and Occupations 26: 107-28. [CrossRef]

Ruys, Maarten. 2017. Advies Voor Een Herstart Voor het Huis Voor Klokkenluiders. Advies, Onafhankelijk Onderzoek en Preventie (Advice for a New Start for the Dutch House for Whistleblowers: Advice, Independent Investigation and Prevention). Available online: https://huisvoorklokkenluiders.nl/wpcontent/uploads / 2017/12 / Advies-voor-een-herstart-voor-het-Huis-voor-klokkenluiders-dec-2017.pdf (accessed on 22 June 2018).

SEC. 2017. Annual Report to Congress: Whistleblower Program. Washington: Securities and Exchange Commission.

Smith, Rodney. 2014. Whistleblowing and Suffering. In International Handbook on Whistleblowing Research. Edited by Alexander J. Brown, David Lewis, Richard E. Moberly and Wim Vandekerckhove. Cheltenham: Edward Elgar Publishing, pp. 230-49.

UNODC. 2015. Resource Guide on Good Practices in the Protection of Reporting Persons. Vienna: UNODC.

van der Velden, Peter G., Mauro Pecoraro, Mijke S. Houwerzijl, and Erik van der Meulen. 2018. Mental health problems among whistleblowers: A comparative study. Psychological Reports. [CrossRef] [PubMed]

Vandekerckhove, Wim. 2010. European whistleblowing policies: Tiers or tears? In A Global Approach to Public Interest Disclosure: What Can We Learn from Existing Whistleblowing LEGISLATION and research? Edited by David B. Lewis. Cheltenham: Edward Elgar, pp. 15-35.

Vandekerckhove, Wim, Alexander J. Brown, Richard E. Moberly, and David Lewis. 2014. Strategic issues in whistleblowing research. In International Handbook on Whistleblowing Research. Edited by Alexander J. Brown, David Lewis, Richard E. Moberly and Wim Vandekerckhove. Cheltenham: Edward Elgar Publishing, pp. 522-30.

Vaughn, Robert G. 2012. The Successes and Failures of Whistleblower Laws. Cheltenham: Edward Elgar.

Voskuil, Koen. 2017. Huis voor Klokkenluiders Stort in Elkaar (Dutch House for Whistleblowers Collapses). AD, December 14. Available online: https:/ / www.ad.nl/binnenland/huis-voor-klokkenluiders-stort-inelkaar a264c38e.X (accessed on 22 June 2018).

(C) 2018 by the authors. Licensee MDPI, Basel, Switzerland. This article is an open access article distributed under the terms and conditions of the Creative Commons Attribution (CC BY) license (http:/ / creativecommons.org/licenses/by/4.0/). 